Vol. 90 , No. 3

\title{
A MULTIPLE-CHANNEL COCHLEAR IMPLANT: AN EV ALUATION USING NONSENSE SYLLABLES
}

\author{
Y'IT CHOW TONG, BE, PhD \\ RichaRD C. DOWELI, BSc, DipAud
}

\author{
Graeme M. Clark, PhD, FrCS \\ LOIS F. MARTIN, BSc, DipAud \\ Peter M. SEligman, BE, PhD \\ East Melbourne, Alstralia
}

\author{
Peter A. BUSBY, MA \\ JAMES F. PATRICK, MSc
}

A studv using nonsense svilables has shown that a multiple-channel cochlear implant with speech processor is effective in providing information about voicing and manner and to a lesser extent place distinctions. These distinctions supplement lipreading cues. Furthermore, the average percentage improvements in overall identification scores for multiple-channel electrical stimulation and lipreading compared to lipreading alone were $71 \%$ for a laboratory-based speech processor and $122 \%$ for a wearable unit.

\section{INTRODUCTION}

Patients with a profound or total hearing loss do not get satisfactory help with a hearing aid. Consequently, there has been interest in producing hearing artificially by electrical stimulation of residual auditory nerve fibers, and recent studies have shown patients benefit by single channel ${ }^{1-3}$ or multiple-channel ${ }^{4-6}$ stimulation. This has been demonstrated by a variety of tests which have included the Utley and Norton speechreading measure, ${ }^{1}$ the Craig lipreading inventory, ${ }^{2}$ closed-set spondaic word lists. ${ }^{2.4}$ rowel identification, ${ }^{2.6}$ consonant identification, ${ }^{3}$ phonetically-balanced word lists, and everyday sentence lists. ${ }^{7}$

In order to evaluate the multiple-channel cochlear implant and speech processor developed at the University of Melbourne, ${ }^{8.9}$ we have considered it desirable to use nonsense syllables with a vowelconsonant-rowel (VCV) structure as a test procedure. We have done this as these syllables have been used to evaluate and improve the speech processing strategy used with our device, ${ }^{6.9}$ and consonant confusion tests using these syllables have been used to assess communication skills in normal and hard of hearing subjects. ${ }^{10,11}$

\section{METHODS}

Two patients with a total hearing loss were implanted with multiple-channel receiver-stimulator devices on August 1, 1978, and July 17. 1979. respectively. The first patient had a sudden hearing loss following a head injury 18 months prior to surgery. Pure-tone audiometry under headphones and free-field revealed no hearing at any frequency, and the patient consequently received no benefit from a hearing aid. Polytome $x$-ravs of the temporal bone demonstrated a fracture involving the superior semicircular canal, and electrical stimulation of the promontory was positive. The second patient had a progressive hearing loss. He had interstitial keratitis at the age of 19 , and was involved in a bomb blast in 1944. For 13 years prior to surgery, pure-tone audiometry had shown no residual hearing. When tested in 1978 pure-tone audiometry under headphones showed no hearing in the left or operated ear, and in the right ear a threshold of $105 \mathrm{~dB}$ HTL at $0.5 \mathrm{kHz}$ and $90 \mathrm{~dB}$ HTL at $0.25 \mathrm{kHz}$. Speech audiometry under headphones at intensities of $120 \mathrm{~dB}$ SPL gave $0 \%$ scores. This patient received no benefit from a hearing aid. Electrical stimulation of the promontory was also positive.

The receiver-stimulator units were implanted in a bed created in the mastoid bone. ${ }^{12}$ They provided ten channels of stimulation, with independent control of the pulse rate and current level on each channel. ${ }^{13}$ Electrical stimulation was produced with biphasic current pulses with the leading phase negative and each phase fixed at approximately $180 \mu \mathrm{s}$. The current levels were varied from $70 \mu \mathrm{A}$ in fifteen $70 \mu \mathrm{A}$ steps to approximately $1 \mathrm{~mA} .^{13}$ Power and data were transmitted through the skin by inductive coupling. The electrode arrays from the receiver-stimulator units were inserted into the scala tympani of the basal turn of the cochlea through the round window, and passed for a distance of $20-25 \mathrm{~mm}$. The electrode arrays had 20 individual electrodes so that ten channels of stimulation could be obtained, using alternate electrodes as a common ground. The array was fabricated from Teflon ${ }^{\circledR}$-coated platinum wires with a bare diameter of .025 $\mathrm{mm}$. The wires were enclosed in a Silastic ${ }^{\circledR}$ tube (Dow Corning) with an outside diameter of $0.6 \mathrm{~mm}$, and connected to $0.3 \mathrm{~mm}$ strips of platinum foil. These strips were then wrapped around the Silastic tube, and the free ends welded together. ${ }^{14}$

Following the operation on the first patient, electrical stimulus thresholds for 1000 pulse's stimuli were obtained and these varied from $67 \mu \mathrm{A}$ to $402 \mu \mathrm{A}$ for the different electrodes, and there was a dynamic range of approximately $450 \mu \mathrm{A}$. A series of psychophysical tests was then carried out. These showed that he experienced a change in vowel color and sharpness with the position of the electrode, a variation in pitch with pulse rate, and an increase in loudness with current level. ${ }^{6}$ It therefore appeared that a possible speech processing strategy was to transform the spectral emphasis of a speech signal to electrode position, the fundamental frecuency to pulse rate, and the speech signal energy to current level.

This strategy was implemented initially using a laboratorybased speech processor. ${ }^{9}$ In the speech processor the voicing fre(quencr of speech $(\mathrm{FO})$ and its energy $(\mathrm{AO})$ were extracted using a $400 \mathrm{~Hz}$ low-pass filter, and an energy threshold detector of AO was used to determine whether voicing was present or not. In the presence of voicing the pulse rate on electrodes was made proportional to FO. If voicing was absent, a constant low pulse rate was used as it produced a sensation described as "rough" which was similar to a "noise" sensation previously experienced by the patients when they had hearing. In addition, the frequency of the dominant spectral peak in the midfrequency range, called the sec-

From the Department of Otolaryngology, Lniversity of Melbourne. The Royal Victorian Eye and Ear Hospital, East Melbourne. Australia.

REPRINTS - Graeme M. Clarke, PhD. FRCS, Department of Otolaryngology, University of Melbourne, The Royal Victorian Eye and Ear Hospital, East Melbourne. Vic. 3002, Australia. 


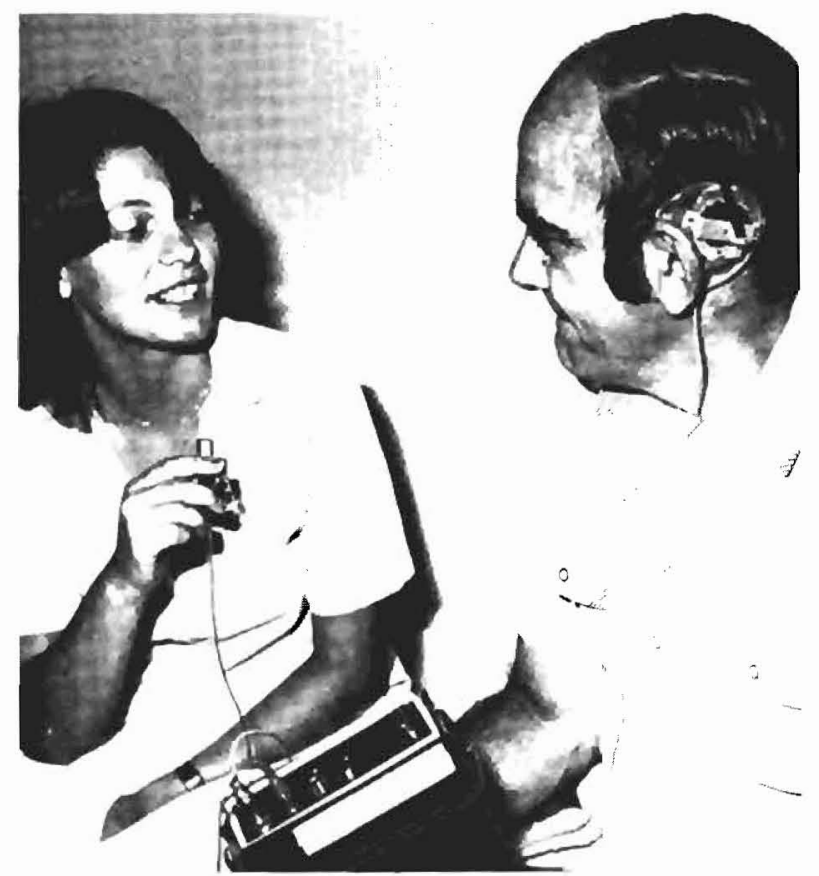

Fig. 1. Photograph of patient 1 using the wearable speech-processor.

ond formant frequency (F2) and the energy (A2) associated with this peak were estimated from the output of a $750-4000 \mathrm{~Hz}$ bandpass filter. For a given F2 estimate, an electrode was selected from a predetermined F2-to-electrode transformation map, which had been constructed by ranking the electrodes from dullest to sharpest, and assigning frequency subbands to these electrodes in an order from lowest to highest. Similarly, the current level was determined on the basis of an A2-to-current level map. The speech parameters were determined every $10 \mathrm{~ms}$, and only one electrode was activated within a $10 \mathrm{~ms}$ time frame.

The laboratory-based speech processor was assessed in the two patients using nonsense syllables constructed from the consonants b. $\mathrm{p}, \mathrm{m}, \mathrm{d}, \mathrm{t}, \mathrm{n}, \mathrm{g}, \mathrm{k}$ in a VCV structure using the vowel a as in "father." The above consonants were selected as they include important homophenous phonemes (phonemes having the same form to the eve as another). For example, $b$, ' $\mathrm{m}$ look the same on the lips as do $\mathrm{d}, \mathrm{t}, \mathrm{n}$ and also $\mathrm{g}, \mathrm{k}$.

The study was carried out in a well-lit room with no sound treatment in three situations: multiple-channel electrical stimulation alone (EO), vision alone (VO) and vision plus multiple-channel electrical stimulation ( $\mathrm{EV})$. The test material was presented by experienced audiologists using live voice at an intensity of 80 dB SPL at the microphone. The sets of nonsense syllables were spoken by both a female with a British accent, and a male with an Australian one. It was considered important to have results for both female and male voices in order to assess the capacity of the speech processor in handling both female and male speaker characteristics which can vary considerably in fundamental and formant frequencies. There was in fact quite a considerable variation in the speaker characteristics of the two testers as the female had a fundamental frequency of $230-240 \mathrm{~Hz}$, and the male a frequency of $100-125 \mathrm{~Hz}$.

The test results were obtained after the patients had been made familiar with each stimulus presentation situation, and the nature of the test material. Each patient was tested on four separate days. Two days were for tests with the female speaker and two for the male speaker, so that an assessment could be made of test-retest reliability. On each day the patient had three test sessions for the stimulus conditions EO, VO, EV. Each session lasted 20-25 minutes, and there was a break of 10-15 minutes between each session. Furthermore, the conditions EO, VO, EV were tested in different order to reduce the effects of learning and fatigue in
TABLE 1. IDENTIFICATION OF CONSONANTS.* LABORATORY-BASED SPEECH PROCESSOR

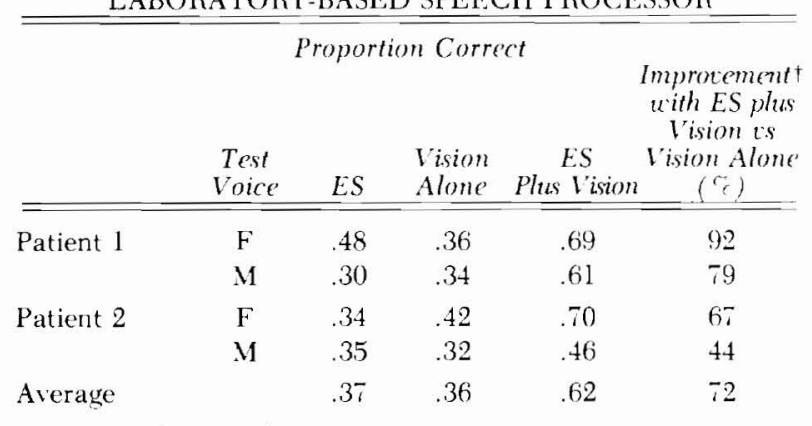

*b, m, p. d. n, t. \&. k.

tImprovement is defined as the difference between the inplant plus vision and vision alone scores divided by the vision alone scores and expressed as a percentage.

Proportion correct - Number of phonemes correctly identified divided by number of times each phoneme was presented (20 stimuli).

ES - Electrical stimulation.

biasing the results. For patient 1 the experimental conditions were: day 1, tester 1 - EO, VO. EV: day 2. tester 2 - EV. EO. VO: dav 3. tester 2-VO. EO. EV: dav 4, tester l - EV. VO. EO For patient 2 the conditions were: day 1 tester 1 - EO. VO. EV: day 2. tester 2 - EV. EO. VO: day 3. tester 2 - EV. EO, VO: day 4. tester 1 - VO, EV. EO. At each session nonsense ssllables were presented at random until all eight consonants had been given ten times, a total of 80 syllables.

The results of the study were recorded as confusion matrices. obtained by plotting the patients responses to each stimulus. From the results, the overall proportion of nonsense svllables correctly identified was calculated. In addition, the proportion of voicing, manner and place distinctions correctly made was determined. It was considered important to assess the value of the inplant in helping the patients to make voicing. manner and place distinctions, as this would be a measure of how effective the derice is in supplementing lip reading cues. Lip reading cues are mainly based on place distinctions, for example. the bilabial plosives $p$ and $b$ have a different place of articulation from the lingua-alveolars $t$ and $d$, and this can be readily seen on the lips. Therefore. if adequate voicing distinctions are provided by electrical stimulation, this will greatly assist in communication. Furthermore, manner distinictions will be of help as these are also not readily visible on the lips, and could help distinguish the plosive $b$ from the nasal $m$

A wearable speech-processor (Fig. 1) was also constructed to provide similar processing strategies to the laboratory-based device. It was tested in the same way although the stimulus conditions were not varied and the order was EV, VO. EO. It was considered that this would 1) maximize the fatigue effect for EO. and 2) there would be a better practice effect for VO following EV rather than for EO following EV. Presenting the conditions this way would therefore be more likely to give better results for $\mathrm{VO}$ rather than EO. Furthermore, due to staff changes another audiologist carried out the male voice tests. The results were also plotted as confusion matrices.

\section{RESULTS}

The results of the nonsense syllable tests for the laboratory-based speech processor are summarized in Table 1. The order of EO, VO, EV had no significant effect on the results, and test-retest reliability was good, especially for patient 1. Furthermore. it can be seen from Table 1 that when tested with female and male voices, the use of the multiplechannel cochlear implant led to a very significant improvement in both patients' abilities to speech- 
TABIE 2. VOICING, MANNER AND PLACE DISTINCTIONS. LABORATORY-BASED SPEECH PROCESSOR

\begin{tabular}{|c|c|c|c|c|c|}
\hline \multicolumn{6}{|c|}{ Proportion Correct } \\
\hline & $\begin{array}{c}\text { Test } \\
\text { Voice }\end{array}$ & & $\begin{array}{c}\text { ES } \\
\text { Alone }\end{array}$ & $\begin{array}{l}\text { Vision } \\
\text { Alone }\end{array}$ & $\begin{array}{c}\text { Es } \\
\text { plus } \\
\text { Vision } \\
\end{array}$ \\
\hline \multirow[t]{6}{*}{ Patient 1} & $\mathrm{~F}$ & Voicing & .94 & .62 & .98 \\
\hline & & Manner & .75 & .60 & .73 \\
\hline & & Place & .63 & .78 & .89 \\
\hline & $M$ & Voicing & .83 & .59 & .86 \\
\hline & & Manner & .66 & .63 & .76 \\
\hline & & Place & .51 & .71 & .88 \\
\hline \multirow[t]{6}{*}{ Patient 2} & $\mathrm{~F}$ & Voicing & .86 & .65 & .96 \\
\hline & & Manner & .71 & .64 & .77 \\
\hline & & Place & .54 & .84 & .93 \\
\hline & .11 & Voicing & .71 & .54 & .68 \\
\hline & & Manner & .76 & .66 & .66 \\
\hline & & Place & .53 & .72 & .84 \\
\hline
\end{tabular}

read compared to vision alone. This improvement varied from 44 to $92 \%$, with an average of $72 \%$.

Furthermore, an analysis of the results to determine the proportion of voicing. manner and place distinctions correctly identified are summarized in Table 2. From this it can be seen that there was a consistent trend for the scores to be significantly better with voicing and manner distinctions for electrical stimulation alone rather than lipreading alone. There was a further improvement in the scores for voicing and manner distinctions when using electrical stimulation in combination with lipreading. Furthermore, although the place distinction results were poorer for electrical stimulation alone compared to lipreading alone, electrical stimulation was in fact a help when used in combination with lipreading as the combined scores for the place distinction were in fact better than with lipreading alone.

The results of testing the wearable speech processor on patient 1 are summarized in Table 3 . The test-retest reliability was good. Table 3 shows that when the wearable speech processor was used in conjunction with lipreading, the scores were significantly better than with lipreading alone. The improvements were $156 \%$ for the female speaker and $92 \%$ for the male. When the results were analyzed

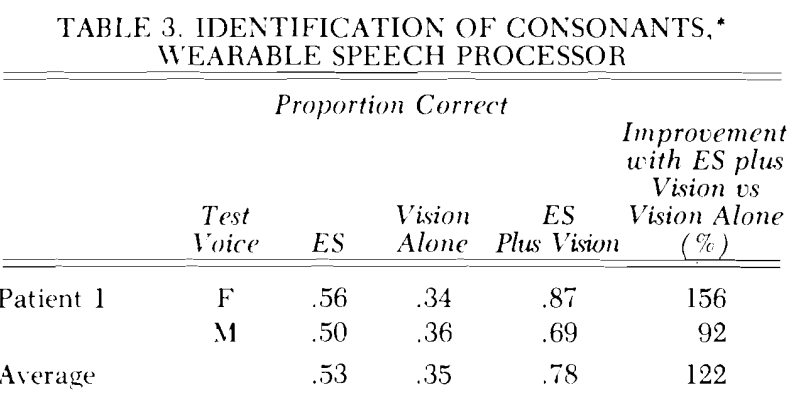

*b. m. p, d. n. t, g. k.

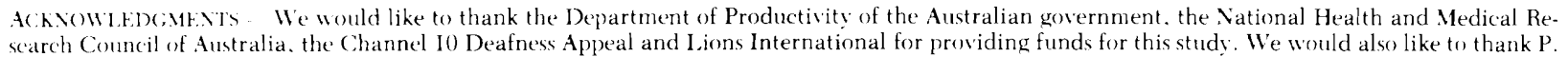
scarch Conncil of Australia. the Channel I0 Deafness Appeal and I.ions Internat
Blames, C. Cocok. L. Cole. R. Walkerden and Miss J. Maher for their help.

REFERENCES

1. House WF, Berliner K. Crary WI, et al. Cochlear implants. Ann Otol Rhinol Laryngol 1976: 85 Suppl 27.
TABLE 4. VOICING, MANNER AND PLACE DISTINCTIONS, WEARABLE SPEECH PROCESSOR

\begin{tabular}{|c|c|c|c|c|c|}
\hline & & perta & & & \\
\hline & $\begin{array}{c}\text { Test } \\
\text { Voice }\end{array}$ & & $\begin{array}{c}E S \\
\text { Alone }\end{array}$ & $\begin{array}{l}\text { Vision } \\
\text { Alone }\end{array}$ & $\begin{array}{c}\text { ES } \\
\text { plus } \\
\text { Vision } \\
\end{array}$ \\
\hline & & Voicing & .94 & .64 & .98 \\
\hline & $\mathrm{F}$ & Manner & .83 & .66 & .93 \\
\hline & & Place & .71 & .80 & .94 \\
\hline 1 & & Voicing & .82 & .62 & .90 \\
\hline & M & Manner & .86 & .73 & .85 \\
\hline & & Place & .62 & .80 & .85 \\
\hline
\end{tabular}

to determine the proportion of voicing, manner and place distinction correctly identified it was found (Table 4) that voicing and manner distinctions were significantly better with multiple-channel electrical stimulation alone compared to lipreading alone, and the scores for electrical stimulation plus lipreading were either as good as electrical stimulation alone or better. Furthermore, although the place distinctions with electrical stimulation were not as good as those with lipreading, they were nevertheless significant, and in the combined electrical stimulation and lipreading situation they were better than with lipreading alone.

\section{DISCUSSION}

The findings in this study show that a multiplechannel cochlear implant and speech processor which extracts the voicing frequency and energy, and the frequency and energy of the dominant spectral peak in the midfrequency range are effective in providing help with voicing and manner distinctions, and to a lesser extent with place information. Help with voicing and manner distinctions should supplement lipreading cues in understanding running speech. Furthermore, it was also shown that the overall scores were significantly better when using multiple-channel electrical stimulation in conjunction with lipreading compared to lipreading alone, and the improvements varied from 44 to $92 \%$ for the laboratory-based speech processor, and from 92 to $156 \%$ for the wearable processor. The improved performance of the wearable processor may have been due to a learning effect, and the fact that a different male voice was used for the tests. The performance was nevertheless significant and indicates that the laboratory-based speech processor strategy had been adequately realized in the wearable unit. It is also of interest that the results for voicing, manner and place distinctions were slightly better in patient 1 for the wearable speech processor when compared with those for the laboratory-based speech processor. 
3. Fourcin AJ. Rosen SM. Moore BCJ. et al. External electrical stimulation of the cochlea: clinical, psychophysical, speechperceptual and histological findings. Br J Aitdiol 1979; 13:85-107.

4. Pialoux P, Chouard CH, Meyer B, Fugain C. Indications and results of the multichannel cochlear implant. Acta Otolaryngol (Strockh) 1979: 87:189-95.

5. Simmonds FB. Mathews RG. Walker MG. White RL. A functioning multi-channel auditory nerve stimulator. Acta Otolaryngol (Stockh) 1979: 87:170-5.

6. Tong YC, Black RC. Clark GM, et al. A preliminary report on a multiple-channel cochlear implant operation. J Laryngol Otol 1979: 93:168-74.

7. Tong YC. Clark GM. Speech comprehension with multiple-channel electrical stimulation of human auditory nerve fibres. J Phýsiol Pharmacol Soc Aust. In press.

8. Clark GM, Tong YC. Black R, Forster IC, Patrick JF, Dewhurst DJ. A multiple-electrode cochlear implant. J Laryngol Otol 1977: 91:935-45
9. Tong YC. Millar JB. Clark GM. Martin LF. Busby PA. Patrick JF. Psychophrsical and speech pereeption studies on two multiple-channel cochlear implant patients. J Laryngol Otol. In press.

10. Wang MD. Reed C.1. Bilger RC. A comparison of the effects of filtering and sensorinerual hearing loss on patients of consonant confusions. J Speech Hear Res 1978: 21:5-36.

11. Frber NP. Auditors, visual. and auditorv-risual recognition of consonants by children with normal and impaired hearing. J Speech Hear Res 1972; 15:413-22.

12. Clark GM. Pyman BC, Bailey QR. The surerery for multiple-electrode cochlear implantations. I Laryngol Otol 1979 93:21:3-23.

13. Clark G.M. Tong YC. Black R. Forster IC. Patrick JF. Dewurst DJ. A multiple-electrode hearing prosthesis for cochlear implantation in deaf patients. Med Prog T'echnol 1977: 5:127-39.

14. Clark GM. Patrick JF. Bailey QF. A cochlear implant round window arras. I Laryngol (otol 1979: 93:107-9. 


\section{University Library}

\section{- M M N E R VA A gateway to Melbourne's research publications}

Minerva Access is the Institutional Repository of The University of Melbourne

Author/s:

Clark, Graeme M.;Tong, Yit Chow;Martin, Lois F.;Busby, Peter A.;Dowell, Richard

C.;Seligman, Peter M.;Patrick, James F.

Title:

A multiple-channel cochlear implant: an evaluation using nonsense syllables

Date:

1981

Citation:

Clark, G. M., Tong, Y. C., Martin, L. F., Busby, P. A., Dowell, R. C., Seligman, P. M., et al. (1981). A multiple-channel cochlear implant: an evaluation using nonsense syllables. Annals of Otology, Rhinology and Laryngology, 90(3), 227-230.

Persistent Link:

http://hdl.handle.net/11343/28742 